\title{
Masticatory Efficiency of Complete Dentures Constructed by different Denture Base Materials
}

\author{
Abd El Aziz O', Saba E.K.A², Mesallati S.A ${ }^{3}$. \\ ${ }^{1}$ Professor of Prosthodontic, Alexandria University Faculty of Dentistry, Alexandria, Egypt \\ ${ }^{2}$ Lecturer of Physical medicine, Rheumatology and Rehabiliatation, Alexandria University Faculty of Medicine, Alexandria, Egypt \\ ${ }^{3}$ BDS, Faculty of Dentistry, Benghazi University, MS, Alexandria University, Egypt
}

\begin{abstract}
Introduction: one of the primary function of the complete denture is to restore masticatory function in the people who have lost their natural teeth, studies have reported that the values for maximum biting force in patient wearing complete dentures were only one-fifth to onesixth the values reached by dentate subjects however, problems such as discomfort and difficulty in chewing certain foods are generally reported by its wearers as a result of a reduced masticatory efficiency, which ranges from $16 \%$ to $50 \%$, when compared to dentate subjects the question arises-do the primary stress-bearing areas actually dissipate the functional forces, or are these forces conveyed elsewhere by the intervening non rigid acrylic base material?.The electromyography has been observed in various investigations that there is a linear relationship between direct force measurement and electromyography activity potential. The aim of the study: The study aims to clinically evaluate the masticatory efficiency of the flexible complete denture and the conventional complete denture. Martials and methods: for the purpose of the study 7 male completely edentulous patients between the ages 45-55 years selected. For each patient two set of complete dentures was fabricated, the First one is flexible denture and the second one is conventional acrylic denture. Surface electrodes from electromyography unit were placed in the region of right and left anterior temporalisand masseter muscles and electromyography activity was recorded. Quantitative parameters were assessed. Quantitative parameter is bite force by electromyography evaluation which was measured after insertion. Result and discussion: Qualitative data were described using number and percent. Quantitative data were described using range (minimum and maximum), mean, standard deviation and median. Significance of the obtained results was judged at the 5\% level. Conclusion; The EMG activity of the masseter muscle higher in flexible denture base than conventional acrylic denture base during clenching on preformed silicon index, and when chewing soft and hard food after two months. The anterior temporalis muscle showed higher activity in flexible denture base than conventional acrylic denture base during clenching on preformed silicon index, when chewing soft food and hard food.
\end{abstract}

Keywords: acrylic denture base, flexible denture base, masticatory activity, electromyography

\section{Introduction}

The loss of natural teeth not only results in aesthetic issues to individuals, but can also seriously risk masticatory function. Long-term dentation could eventually result in bone resorption, temporomandibular disorders or muscle hypo- tonicity which ultimately leads to direct damage to the masticatory process.[1]

Furthermore, a reduction in the physiological secretion of gastric acid is characteristic of the aging human process which reinforces the importance of efficient mastication to start food digestion processes. [2]

One of the primary function of the complete denture is to restore masticatory function in the people who have lost their natural teeth, studies have reported that the values for maximum biting force in patient wearing complete dentures were only one-fifth to one- sixth the values reached by dentate subjects.[3]

However, problems such as discomfort and difficulty in chewing certain foods are generally reported by its wearers as a result of a reduced masticatory efficiency, which ranges from $16 \%$ to $50 \%$, when compared to dentate subjects.[4]

Their chewing, admittedly limited, may predispose these individuals to a variety of problems, such as; inability to chew tough or hard foods, - oral pain, instability of their complete dentures.
Chewing efficiency is reduced when teeth are replaced by complete denture.[5] The bite force measurements can be recorded directly by using a suitable transducer which is a convenient way of assessing the maximum voluntary bite force. Another method to record bite force is indirect evaluation by means of electromyography. It has been observed in various investigations that there is a linear relationship between direct force measurement and electromyography activity potential. [6]Electromyography techniques have permitted more precise assessment of the muscle functions than that was previously possible by clinical observation. [7]

The measurement of bite force can provide useful data for the evaluation of jaw muscle function and activity. It is also an adjunctive value in assessing the performance of dentures.

Technological advances in signal detection and processing have improved the quality of the informationextracted from bite force measurements. [8]

The main goal of this study is to evaluate the masticatory efficiency of flexible complete denture base in comparison with heat cured acrylic dentures. 


\section{International Journal of Science and Research (IJSR) \\ ISSN (Online): 2319-7064 \\ Index Copernicus Value (2013): 6.14 | Impact Factor (2015): 6.391}

\section{Material and Method}

\section{Patient selection}

Seven patients were selected from the department of removable prosthodontics, faculty of dentistry, Alexandria University, having maxillary and mandible edentulous ridges.

For each patient two set of complete dentures were fabricated, the First one is flexible denture and the second one is conventional acrylic denture.

\section{Patient selective criteria}

Inclusive criteria

- Malepatient's age ranging from 45-55 years.

- Free from any systemic or neuromuscular disorder that might affect chewing efficiency of masticatory muscles.

- Free from any tempro-mandibular joint disorder, xerostomia/excessive salivation and abnormal tongue size.

- Class I Angle'- ridge relationship.

\section{Exclusive criteria}

1. Patient with abnormal tongue behavior and/or size

2. Patient with xerostomia or excessive salivation

3. Patients with habits like bruxism, habitual eccentric movements etc. which would compromise the results.

\section{Method}

Steps of construction were made for upper and lower ridges;

1. Preliminary alginate impressions (Cavex impressiona in a stock tray).

2. The impressions were poured with dental plaster to form study casts upon which custom made trays were fabricated in auto-polymerized acrylic resin.

3. Final impression for upper and lower ridges was made by using zinc-oxide (Cavex outline).

4. The impressions were poured using dental stone to obtain the master casts and record blocks consisting of auto polymerized acrylic resin record base and wax occlusion rims were fabricated.

5. Registrations of maxilla-mandibular relations were carried out.

The relation of the maxillary record blocks to the T.M.J was recorded with the face bow and transferred to the semiadjustable articulator.

6. The mandibular record blocks were mounted using interocclusal centric record following the standard procedure.

7. (Acrylic cross-linked, Acrostone, Egypt) teeth were selected, Try-in made and the occlusion carefully checked on the articulator as well as in the patient.

Dentures processed by 2 techniques according to type of denture base material:

Flexible complete dentures processed by injection cast technique.[9]

Conventional acrylic complete dentures.Processed in a water bath curing tank for $1 \frac{1}{2}$ hour at $74^{\circ} \mathrm{c}$ and another 1 hour at $100^{\circ} \mathrm{c}$. Then, the dental flask was cooled to room temperature.
Denture laboratory remounted, finished and polished then, the finished dentures checked for proper extension, retention and stability intra-orally. The patient given a proper program for denture insertion and oral hygiene measures. (Fig. $1 \& 2$ )

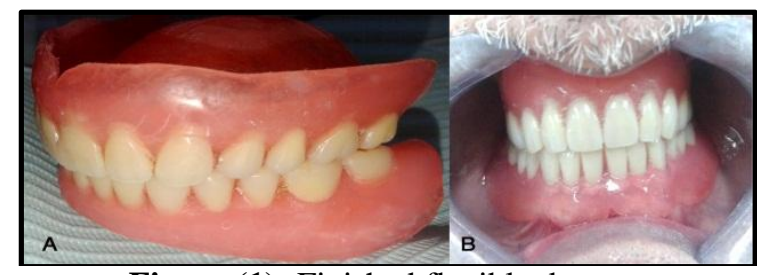

Figure (1): Finished flexible denture A: Extraoral, B: Intraoral.

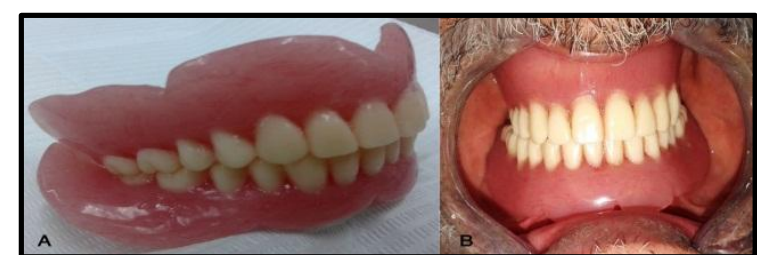

Figure (2): Finished conventional acrylic denture A: Extraoral, B: Intraoral.

Patients was instructed to follow general instructions as they were following for their normal acrylic denture.

The patient was recalled after 48 hours to check for any pressure area causing pain or discomfort. Electromyography evaluation.[10]

Evaluation of masticatory function was performed by measuring muscle activity of the masseter and anterior fibers of the temporalis muscle on both sides for both dentures at the end of the two weeks using electromyography with three types of test foods.[11]

EMG recordings were made after the completely absence of any discomfort, when the patients were presumed to be adapted to their dentures, after one month then two months later.

During all recording, the patients were seated with their head unsupported and were asked to maintain a naturally erect position.

The massetric myoelectric activities of both sides (left and right) were recorded by means of bipolar electrode positioned on the bellies of the muscles parallel to the fiber orientation.

The recording electrodes were approximately $20 \mathrm{~mm}$ apart.

The patient was grounded by grounding electrode by fixing the third electrode on the palm of the patient hand.

Electro-conductive gel was used on the electrode before contacting the skin. 


\section{International Journal of Science and Research (IJSR) \\ ISSN (Online): 2319-7064}

Index Copernicus Value (2013): 6.14 | Impact Factor (2015): 6.391

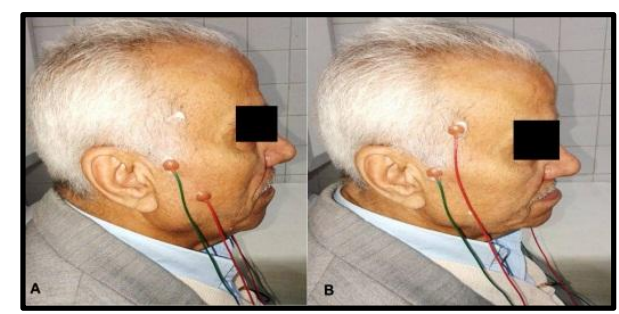

Figure 3: Bipolar electrodes positioned at A: masseter muscle B: Anterior temporalis muscle.

Each patient was instructed to clench on standardized size of preformed silicone index $(13 \times 13 \times 13 \mathrm{~mm})$ made by vinyl polysiloxane material(putty) positioned at premolar region for 30 seconds to measure the muscle activity during clenching.

Then the patient was instructed to chew on standardized size of hard food (raw fresh carrot) $(13 \times 13 \times 13 \mathrm{~mm})$ for ten seconds intervals then the EMG were recorded.

Then the patient was instructed to chew on standardized size of soft food (banana) $(13 \times 13 \times 13 \mathrm{~mm})$ for ten seconds intervals then the EMG were recorded.

The patient chewed the test samples on the right and left sides at ten seconds to swallow before the EMG was recorded.

At the end of the record and before removing the surface electrodes, the positions of the electrodes were marked to be used as a guide for accurate reproducibility.

The previous tasks were separated by a recovery rest period of 2 minutes.

The same procedure was repeated with the anterior temporalis muscle on both sides (right and left).

\section{Results}

Seven patients were selected from the department of removable prosthodontics, faculty of dentistry, Alexandria University, having maxillary and mandible edentulous ridges.

For each patient two set of complete dentures werefabricated, the First one is flexible denture and the second one is conventional acrylic denture.

Seven completely edentulous patients were selected for this study where all the patients received two complete dentures the first one is flexible denture and the second one is conventional acrylic denture.

After using the denture for period of one week with each denture, masticatory function was evaluated by recording the EMG activity for masseter and anterior temporalis muscles during clenching on preformed silicon index, chewing banana and chewing carrot as test foods,one month and two months later.

Data was collected, tabulated and statistically presented as follows;

Table (1); comparison between conventional acrylic denture and flexible denture according to EMG signals (mean values) of masseter muscle during clenching on preformed silicon index after one week, one month, and two months later.

The table shows statistical significant difference between the conventional acrylic denture and flexible denture during clenching with preformed silicon index only after one week $(p=0,011)$, no statistical significant difference between the conventional acrylic denture and flexible denture after one month and two months later.

Table 1: Comparison between the two studied groups

\begin{tabular}{|c|c|c|c|c|c|}
\hline \multirow{2}{*}{ Clench } & \multicolumn{3}{|c|}{ 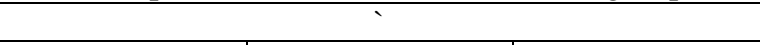 } & \multirow{2}{*}{$\mathrm{F}^{2}$} & \multirow{2}{*}{$\mathrm{P}$} \\
\hline & 1 weak & 1 month & 2 months & & \\
\hline \multicolumn{6}{|l|}{ Conventional $(\mathrm{n}=14)$} \\
\hline Min. - Max. & $97.0-480.0$ & $0.53-442.0$ & $147.0-308.0$ & \multirow{3}{*}{$6.143^{*}$} & \multirow{3}{*}{$0.046^{*}$} \\
\hline Mean \pm SD. & $351.29 \pm 133.63$ & $258.09 \pm 128.78$ & $243.14 \pm 49.21$ & & \\
\hline Median & 400.50 & 272.50 & 242.0 & & \\
\hline Sig. bet. Periods & \multicolumn{3}{|c|}{$\mathrm{p}_{1}=0.074, \mathrm{p}_{2}=0.052, \mathrm{p}_{3}=0.433$} & & \\
\hline B- flixable $(n=14)$ & & & & & \\
\hline Min. - Max. & $0.47-440.0$ & $172.0-453.0$ & $251.0-593.0$ & \multirow{3}{*}{$8.143^{*}$} & \multirow{3}{*}{$0.017^{*}$} \\
\hline Mean \pm SD & $184.82 \pm 116.33$ & $265.29 \pm 80.77$ & $377.57 \pm 124.39$ & & \\
\hline Median & 160.50 & 247.50 & 309.0 & & \\
\hline Sig. bet. Periods & \multicolumn{3}{|c|}{$\mathrm{p}_{1}=0.022^{*}, \mathrm{p}_{2}=0.009^{*}, \mathrm{p}_{3}=0.048^{*}$} & & \\
\hline $\mathrm{Z}$ & $2.528^{*}$ & 0.528 & $3.240^{*}$ & & \\
\hline $\mathrm{P}$ & $0.011^{*}$ & 0.597 & $0.001^{*}$ & & \\
\hline
\end{tabular}

Table (2); comparison between conventional acrylic denture and flexible denture according to EMG signals (mean values) of masseter muscle during chewing soft food after one week, one month, and two months later. chewing soft food only after two months $(p=0,011)$, no statistical significant difference between the conventional acrylic denture and flexible denture after one week $(\mathrm{p}=0,232)$ and one months $(0,597)$.

The table shows statistical significant difference between the conventional acrylic denture and flexible denture during 


\section{International Journal of Science and Research (IJSR) \\ ISSN (Online): 2319-7064}

Index Copernicus Value (2013): 6.14 | Impact Factor (2015): 6.391

Table 2: Comparison between the two studied groups.

\begin{tabular}{|c|c|c|c|c|c|}
\hline \multirow{2}{*}{ Soft } & \multicolumn{3}{|c|}{ Masseter after } & \multirow{2}{*}{$\mathrm{F}^{2}$} & \multirow{2}{*}{$\mathrm{P}$} \\
\hline & 1 weak & 1 month & 2 months & & \\
\hline \multicolumn{6}{|c|}{ Conventional $(\mathrm{n}=14)$} \\
\hline Min. - Max. & $77.0-633.0$ & $0.53-442.0$ & $147.0-308.0$ & \multirow{3}{*}{1.857} & \multirow{3}{*}{0.395} \\
\hline Mean \pm SD. & $307.71 \pm 185.80$ & $258.09 \pm 128.78$ & $243.14 \pm 49.21$ & & \\
\hline Median & 276.0 & 272.50 & 242.0 & & \\
\hline Sig. bet. Periods & \multicolumn{3}{|c|}{$\mathrm{p}_{1}=0.198, \mathrm{p}_{2}=0.433, \mathrm{p}_{3}=0.433$} & & \\
\hline \multicolumn{6}{|l|}{ B- flixable $(n=14)$} \\
\hline Min. - Max. & $56.70-401.0$ & $172.0-453.0$ & $251.0-593.0$ & \multirow{3}{*}{$6.143^{*}$} & \multirow{3}{*}{$0.046^{*}$} \\
\hline Mean \pm SD. & $224.19 \pm 97.49$ & $265.29 \pm 80.77$ & $377.57 \pm 124.39$ & & \\
\hline Median & 193.0 & 247.50 & 309.0 & & \\
\hline Sig. bet. Periods & \multicolumn{3}{|c|}{$\mathrm{p}_{1}=0.221, \mathrm{p}_{2}=0.013^{*}, \mathrm{p}_{3}=0.048^{*}$} & & \\
\hline $\mathrm{Z}$ & 1.195 & 0.528 & $3.240^{*}$ & & \\
\hline $\mathbf{P}$ & 0.232 & 0.597 & 0.001* & & \\
\hline
\end{tabular}

Table (3); comparison between conventional acrylic denture and flexible denture according to EMG signals (mean values) of masseter muscle during chewing hard food after one week, one month, and two months later.
The table shows statistical significant difference between the conventional acrylic denture and flexible denture during chewing hard food only after two months $(p=0,026)$, no statistical significant difference between the conventional acrylic denture and flexible denture after one week $(\mathrm{p}=0,232)$ and one months $(0,251)$.

Table 3: Comparison between the two studied groups

\begin{tabular}{|c|c|c|c|c|c|}
\hline \multirow{2}{*}{ Hard } & \multicolumn{3}{|c|}{ Masseter after } & \multirow{2}{*}{$\mathrm{F}_{\mathrm{c}}^{2}$} & \multirow{2}{*}{$\mathrm{P}$} \\
\hline & 1 weak & 1 month & 2 months & & \\
\hline \multicolumn{6}{|l|}{ Conventional $(\mathrm{n}=14)$} \\
\hline Min. - Max. & $66.70-437.0$ & $0.71-698.0$ & $177.0-401.0$ & \multirow{3}{*}{1.857} & \multirow{3}{*}{0.395} \\
\hline Mean \pm SD. & $313.12 \pm 109.28$ & $383.86 \pm 224.46$ & $292.57 \pm 56.94$ & & \\
\hline Median & 327.50 & 380.0 & 303.50 & & \\
\hline Sig. bet. Periods & \multicolumn{3}{|c|}{$\mathrm{p}_{1}=0.363, \mathrm{p}_{2}=0.510, \mathrm{p}_{3}=0.124$} & & \\
\hline \multicolumn{6}{|l|}{ B- flixable $(n=14)$} \\
\hline Min. - Max. & $0.20-520.0$ & $222.0-757.0$ & $210.0-621.0$ & \multirow{3}{*}{5.571} & \multirow{3}{*}{0.062} \\
\hline Mean \pm SD. & $249.01 \pm 168.67$ & $341.79 \pm 153.60$ & $388.14 \pm 128.19$ & & \\
\hline Median & 210.0 & 293.60 & 355.0 & & \\
\hline Sig. bet. Periods & $\mathrm{p}_{1}=0.272, \mathrm{p}_{2}=0.030$ & $\mathrm{p}_{3}=0.221$ & & & \\
\hline $\mathrm{Z}$ & 1.195 & 1.149 & $2.229^{*}$ & & \\
\hline $\mathrm{P}$ & 0.232 & 0.251 & $0.026^{*}$ & & \\
\hline
\end{tabular}

Table (4); comparison between conventional acrylic denture and flexible denture according to EMG signals (mean values) of anteriortemporalis muscle during clenching on preformed silicon index
The table shows no statistical significant difference of the anterior temporalis muscle between the conventional acrylic denture and flexible denture during clenching on preformed silicon index.

Table 4: Comparison between the two studied groups.

\begin{tabular}{|c|c|c|c|c|c|}
\hline \multirow{2}{*}{ Clench } & \multicolumn{3}{|c|}{ Temporalis after } & \multirow{2}{*}{$\mathrm{F}_{\square}^{\square}$} & \multirow{2}{*}{$\mathrm{P}$} \\
\hline & 1 weak & 1 month & 2 months & & \\
\hline \multicolumn{6}{|l|}{ Conventional $(\mathrm{n}=14)$} \\
\hline Min. - Max. & $0.65-420.0$ & $0.47-232.0$ & $145.0-411.0$ & \multirow{3}{*}{4.000} & \multirow{3}{*}{0.135} \\
\hline Mean \pm SD. & $144.73 \pm 119.89$ & $164.53 \pm 73.91$ & $228.57 \pm 73.24$ & & \\
\hline Median & 159.50 & 198.50 & 200.0 & & \\
\hline Sig. bet. Periods & \multicolumn{3}{|c|}{$\mathrm{p}_{1}=0.331, \mathrm{p}_{2}=0.041^{*}, \mathrm{p}_{3}=0.433$} & & \\
\hline B- flixable $(n=14)$ & & & & & \\
\hline Min. - Max. & $0.61-393.0$ & $99.0-497.0$ & $107.0-578.0$ & \multirow{3}{*}{$15.429^{*}$} & \multirow{3}{*}{$<0.001^{* \prime}$} \\
\hline Mean \pm SD. & $131.61 \pm 114.96$ & $216.21 \pm 103.91$ & $303.07 \pm 151.67$ & & \\
\hline Median & 135.0 & 210.50 & 250.50 & & \\
\hline Sig. bet. Periods & \multicolumn{3}{|c|}{$\mathrm{p}_{1}=0.008^{*}, \mathrm{p}_{2}=0.004^{*}, \mathrm{p}_{3}=0.286$} & & \\
\hline $\mathrm{Z}$ & 0.781 & 1.356 & 1.425 & & \\
\hline $\mathrm{P}$ & 0.435 & 0.175 & 0.154 & & \\
\hline
\end{tabular}

Table (5); comparison between conventional acrylic denture and flexible denture according to EMG signals (mean values) of anterior temporalis muscle during chewing soft food after one week, one month, and two months later.
The table shows statistical significant difference between the conventional acrylic denture and flexible denture during chewing soft food only after two months $(p=0,009)$, no statistical significant difference between the conventional

\section{Volume 5 Issue 6, June 2016 www.ijsr.net}




\section{International Journal of Science and Research (IJSR) \\ ISSN (Online): 2319-7064}

Index Copernicus Value (2013): 6.14 | Impact Factor (2015): 6.391

acrylic denture and flexible denture after one week $(\mathrm{p}=0,783)$ and one months $(0,783)$

Table 5: Comparison between the two studied groups.

\begin{tabular}{|c|c|c|c|c|c|}
\hline \multirow{2}{*}{ Soft } & \multicolumn{3}{|c|}{ Temporalis after } & \multirow{2}{*}{$\mathrm{F}_{\square}^{\square}$} & \multirow{2}{*}{$\mathrm{P}$} \\
\hline & 1 weak & 1 month & 2 months & & \\
\hline \multicolumn{6}{|l|}{ Conventional $(\mathrm{n}=14)$} \\
\hline Min. - Max. & $0.59-380.0$ & $0.53-307.0$ & $92.10-360.0$ & \multirow{3}{*}{$6.143^{*}$} & \multirow{3}{*}{$0.046^{*}$} \\
\hline Mean \pm SD. & $152.49 \pm 122.48$ & $205.52 \pm 93.51$ & $216.08 \pm 70.25$ & & \\
\hline Median & 188.50 & 224.50 & 211.50 & & \\
\hline Sig. bet. Periods & \multicolumn{3}{|c|}{$\mathrm{p}_{1}=0.245, \mathrm{p}_{2}=0.041^{*}, \mathrm{p}_{3}=0.245$} & & \\
\hline B- flixable $(n=14)$ & & & & & \\
\hline Min. - Max. & $0.33-397.0$ & $105.0-437.0$ & $187.0-757.0$ & \multirow{3}{*}{$9.418^{*}$} & \multirow{3}{*}{$0.009^{*}$} \\
\hline Mean \pm SD. & $143.56 \pm 130.64$ & $232.0 \pm 99.53$ & $359.71 \pm 175.93$ & & \\
\hline Median & 152.0 & 213.0 & 300.50 & & \\
\hline Sig. bet. Periods & \multicolumn{3}{|c|}{$\mathrm{p}_{1}=0.005^{*}, \mathrm{p}_{2}=0.004^{*}, \mathrm{p}_{3}=0.116$} & & \\
\hline $\mathrm{Z}$ & 0.276 & 0.276 & $2.620^{*}$ & & \\
\hline $\mathrm{P}$ & 0.783 & 0.783 & $0.009^{*}$ & & \\
\hline
\end{tabular}

Table (6); comparison between conventional acrylic denture and flexible denture according to EMG signals (mean values) of temporalis muscle during chewing hard food after one week, one month, and two months later.
The table shows no statistical significant difference of the anterior temporalis between the conventional acrylic denture and flexible denture during chewing hard food after one week $(\mathrm{p}=0,550)$, one month $(\mathrm{p}=0,765)$, two months $(\mathrm{p}=0,060)$.

Table 6: Comparison between the two studied groups

\begin{tabular}{|c|c|c|c|c|c|}
\hline \multirow{2}{*}{ Hard } & \multicolumn{3}{|c|}{ Temporalis after } & \multirow{2}{*}{$\mathrm{F}_{\square}^{\square}$} & \multirow{2}{*}{$\mathrm{P}$} \\
\hline & 1 weak & 1 month & 2 months & & \\
\hline \multicolumn{6}{|l|}{ Conventional $(n=14)$} \\
\hline Min. - Max. & $0.48-477.0$ & $0.53-543.0$ & $65.0-440.0$ & \multirow{3}{*}{2.286} & \multirow{3}{*}{0.319} \\
\hline Mean \pm SD. & $192.44 \pm 163.87$ & $286.31 \pm 144.54$ & $248.87 \pm 100.34$ & & \\
\hline Median & 210.0 & 304.50 & 247.0 & & \\
\hline Sig. bet. Periods & \multicolumn{3}{|c|}{$\mathrm{p}_{1}=0.272, \mathrm{p}_{2}=0.221, \mathrm{p}_{3}=0.177$} & & \\
\hline \multicolumn{6}{|l|}{ B- flixable $(n=14)$} \\
\hline Min. - Max. & $0.51-720.0$ & $80.0-687.0$ & $221.0-614.0$ & \multirow{3}{*}{$10.857^{*}$} & \multirow{3}{*}{$0.004^{*}$} \\
\hline Mean \pm SD & $181.77 \pm 216.37$ & $308.50 \pm 176.70$ & $344.29 \pm 127.92$ & & \\
\hline Median & 120.50 & 253.0 & 303.0 & & \\
\hline Sig. bet. Periods & \multicolumn{3}{|c|}{$\mathrm{p}_{1}=0.048^{*}, \mathrm{p}_{2}=0.041^{*}, \mathrm{p}_{3}=0.900$} & & \\
\hline $\mathrm{Z}$ & 0.597 & 0.229 & 1.884 & & \\
\hline $\mathrm{P}$ & 0.550 & 0.765 & 0.060 & & \\
\hline
\end{tabular}

${ }^{\mathrm{F}}$ : Chi square for Friedman test for comparing between the different periods

$\mathrm{Z}$ : Z for Mann Whitney test for comparing between the two groups

Sig. bet. periods was done using Wilcoxon signed ranks test $\mathrm{p}_{1}$ : $\mathrm{p}$ value for comparing between 1 weak and 1 month $\mathrm{p}_{2}$ : $\mathrm{p}$ value for comparing between 1 weak and 2 months $\mathrm{p}_{3}$ : $\mathrm{p}$ value for comparing between 1 month and 2 months *: Statistically significant at $\mathrm{p} \leq 0.05$

\section{Discussion}

Masticatory function is generated by rhythmic contraction of masticatory system. Several other parameters are important, such as number of teeth and quality of occlusal contacts and health of the masticatory system. [12]

Masticatory forces in completely edentulous mouth directly depends on the size of muscles creating the forces, their position in the mandible, type of chewing, shape of the edentulous alveolar ridge and the degree of intermaxillary separation.

Bite force in complete denture wearers are significantly decreased in relation to people with natural teeth. There is a fundamental difference in the distribution of the functional energy in complete denture wearers and subjects with intact teeth. Reduction of masticatory efficiency in denture wearers may be caused by irregular flow of energy during mastication. [13]

In this study, seven completely edentulous Patients were selected with their age ranging from 45 to 55 (mean age of 50 years) to avoid muscle changes due to senility. There is variation in muscle efficiency due to age, as the patients in the same age group show almost the same muscle efficiency. [14]

Masticatory performances decrease with age as other motion activities. Muscle fatigue accompanied by bite force diminution and tongue-motor decline are often found in elderly persons. These changes that occur during healthy aging depress the masticatory ability and may provoke swallowing difficulties. [15]

The selected patients were male to avoid the difference in muscle efficiency between different sexes. [16] There are a variety of factors may contribute to preference of male selection [17], including hormonal alternations [18], blood pressure [19] and psychological factors. [20]

\section{Volume 5 Issue 6, June 2016 www.ijsr.net}




\section{International Journal of Science and Research (IJSR) \\ ISSN (Online): 2319-7064}

Index Copernicus Value (2013): 6.14 | Impact Factor (2015): 6.391

Furthermore, elderly females showed a lower rate of chewing efficiency than males. [21]

Patients with systemic disease or neuromuscular disorders were excluded to avoid any effect on the muscle tone and hence resultant masticatory efficiency. [22]

Patients with tempro-mandibular joint dysfunction were also excluded to avoid any disturbance in muscle behavior. [23]

Moreover; patients with abnormal ridge relationship were avoided because dentate subjects with normal occlusion were found to have a better masticatory efficiency than subjects with malocclusions. [24]

The abnormal tongue behavior or size and/or xerostomia or excessive salivation were exclusive factors during the patients selection, as that may affect the dentures stability, retention and subsequent the patient's satisfaction rating.[25]

Incorporation of accurate centric relation was important not only for mounting lower cast but also to avoid jeopardization of retention, stability and interference with mastication. [26, 27] Ideally, to establish bilateral balanced occlusal scheme, fully adjustable articulator should be used. However; it is not always available. Hanau model semiadjustable articulator was used.

Acrostone cross- linked acrylic teeth were used in this study to standardize the type of teeth used in all the constructed dentures in this study. Cross-linking improves strength and wear resistance which enhances the ability of acrylic teeth to maintain a stable occlusal relationship [28] that produce better chewing and masticatory performance.

Maxillary and mandibular removable flexible complete denture wears fabricated (acrylfast) for each patient using injection cast technique.

Flexible denture used in this study was reported no denture sore-mouth and the better comfort level, better retention and stability in flexible dentures due to low modulus elasticity of this material. [29]

Maxillary and mandibular removable acrylic complete denture wear fabricated for each patient using the standardized conventional technique.

Finished dentures were tried in the patient's mouth at the time of delivery to check for any occlusal discrepancies and border extensions that could impair denture stability as well as retention that might affect masticatory efficiency during the initial learning period after denture insertion.

Same patients received both types of denture alternatively to avoid bias resulting from individual variation. [30]

Electromyography (EMG) has also been used to assess the masticatory function of conventional and flexible complete removable denture.

-The masseter and anterior temporalis muscles on both sides were evaluated because they are the largest and strongest of the masticatory muscles, the most superficial and are accessible to surface EMG examination.

The surface EMG recording provided as safe, easy and noninvasive method that allowed objective quantification of the energy of the muscle. [31]

The objective evaluation of masticatory efficiency was made during chewing different types of food, either hard and soft (carrot and banana. [32]

Carrot and banana were chosen as test food material, because of their reliable natural test and their suitability for complete denture wearers who could easily crush and comminute those. [33]

Moreover, both carrot and banana were cut into small and symmetrical pieces of about $13 \mathrm{~mm}$ to eliminate the influence of different food size on muscular efficiency. [34]

Standardized measure of preformed silicon index $13 \mathrm{~mm}$ was used to measure the muscle activity during clenching.

To ensure muscle relaxation during EMG recording, the patients were seated in an upright position to avoid the postural effect on the recorded muscle activities. The site of electrode placement was rubbed with abrasive gel and cleansed with a cotton pellet moisten with alcohol before electrode placement to remove excess oil that reduces skin electrical resistance. This enhanced contact with the electrodes to obtain signals of good quality. An electro conductive gel was used to improve conductivity[35].

For this study, the disposable bipolar electrodes were positioned on the bellies of the muscles parallel to the fiber orientation because higher electrical activity was recorded from electrode pairs parallel to the muscle fibers. The interelectrode distance used was fixed at $20 \mathrm{~mm}$ to avoid variability in the results. When bipolar electrodes are being applied on relatively small muscles the interlectrode distance should not exceed 1/4 of muscle fiber length. In this way unstable recordings, due to tendon and motor endplate effects can be avoided. [36]

The end of the record and before removing the surface electrodes, the positions of electrodes were marked to be used as a guide for accurate reproducibility.[36]

Also the patients participated in this study were evaluated at different follow up period. Each denture was evaluated within one week, one month and two months periods. Those were thought to be sufficient periods of time forevaluation as confirmed by Hein AT, 2013. [37]

The results of this study showed a significant for masticatory function by EMG between studied acrylic and flexible denture base with higher mean scores of EMG activity for the flexible denture for masseter muscle during clenching on preformed silicon index, when chewing soft and hard food after two months. .this result agrees with Wostmann et al. who conclude that the flexible dentures much more comfortable for the patient.[38] 


\section{International Journal of Science and Research (IJSR) \\ ISSN (Online): 2319-7064}

Index Copernicus Value (2013): 6.14 | Impact Factor (2015): 6.391

This result agree with Karakazis $\mathrm{HC}$ and Kossion AE who reported that the Chewing efficiency showed marked increased by time infavor to the conventional acrylic because improving denture adaptation which may be due to the neuromuscular control which is gradually and slowly generated by time, i.e. the longer the period of denture wearing, the better the neuromuscular control gained. [31]

The result of this study showed that the EMG activity of the masseter and anterior temporalis muscles during chewing hard food higher than chewing soft food. This finding is also agree with van der Bilt et al, [39] who stated that harder food consistency required higher muscle activity levels due to higher muscle force needed to comminute hard food.

The mean EMG activity increased by the time in both conventional acrylic denture base and flexible denture base either in masseter and anterior temporalis muscles. this result agree with Karakazis $\mathrm{HC}$ and Kossion $\mathrm{AE}$ who reported that the Chewing efficiency showed marked increased by time infavor to the conventional acrylic because improving denture adaptation which may be due to the neuromuscular control which is gradually and slowly generated by time, i.e. the longer the period of denture wearing, the better the neuromuscular control gained. [33]

\section{Conclusion}

Within the limitations of this study of short follow up periods of conventional acrylic complete denture and flexible complete denture, the results lead to the following conclusions;

- EMG activity of the masseter muscle higher when clenching on preformed silicon index in conventional acrylic denture base.

- EMG activity of the anterior temporalis muscle higher when chewing soft food in conventional acrylic denture base.

- In flexible denture base the EMG activity of the masseter and anterior temporalis muscles high during clenching on preformed silicon index, and when chewing soft and hard food.

- The EMG activity of the masseter muscle higher in flexible denture base than conventional acrylic denture base during clenching on preformed silicon index, and when chewing soft and hard food after two months.

- Flexible denture base higher EMG activity of the temporalis muscle when chewing soft food.

- Greater muscle activity of the masseter and anterior temporalis when chewing hard food

- The masseter muscle shows higher muscle activity compared to anterior temporalis muscle.

- The anterior temporalis muscle showed higher in activity in flexible denture base thanconventional acrylic denture base during clenching on preformed silicon index ,when chewing soft food and hard food.

- Chewing efficiency showed marked increased by time infavor to the conventional acrylic denture base and flexible denture base.

\section{References}

[1] Goiato MC, Garcia AR, Dos Santos DM, Zuim PR. Analysis of masticatory cycle efficiency in complete denture wearers. J Prosthodont 2010; 19: 10-13.

[2] Farias-Neto A, Mestriner-Junior W, Carreiro-Ada F. Masticatory efficiencyin denture wearers with bilateral balanced occlusion and canine guidance. Braz Dent J 2010; 21: 165-9.

[3] Tata S, Nandeeshwar DB. A clinical study to evaluate and compare the masticatory performance in complete denture wearers with and without soft liners. J Contemp Dent Pract 2012; 13: 787-92.

[4] Van der Bilt A. Assessment of mastication with implications for oral rehabilitation: A review. J Oral Rehabil 2011; 38: 754-80.

[5] Alajbeg IZ, Valentic-Peruzovic M, Alajbeg I, Illes D, Celebic A. The influence of dental status on masticatory muscle activity in elderly patients. Int $\mathrm{J}$ Prosthodont 2005; 18: 333-8.

[6] Tripathi G, A A P, Rajwadha N, Chhaparia N, Sharma A, Anant M. Comparative evaluation of maximum bite force in dentulous and edentulous individuals with different facial forms. J Clin Diagn Res 2014; 8: ZC3740.

[7] Ashraf H. To determine the influence of the completedenture prosthesis on masticatory muscle activity in elderly patients: An in vivo study. International Journal of Prosthodontics and Restorative Dentistry. 2011; 1: 35-40.

[8] Koc D, Dogan A, Bek B. Bite force and influential factors on bite force measurements. Eur J Dent 2010; 4: 223-32.

[9] Col RK Dhiman, Lt Col SK Roy Chowdhury. Midline Fractures in Single Maxillary Complete Acrylic vs Flexible Dentures. MJAFI, Vol. 65, No. 2, 2009.

[10] Mert Uc, ankale1, Burc, in Akog lu1, Yas, ar O” zkan2 and Yasemin Kulak Ozkan. The effect of Different attachment systems with implantretained overdentures on maximum bite force and EMG.Gerodontology. Accepted 7 March 2010.

[11] Ucankalae M, Akoglu B, Ozkan YK. The effect of different attachment systems with implant retained overdentures on maximum bite force and EMG. Gerodontology 2012;29;24-9

[12] Markoviae D,Petrovic. Specifics of mastication withbcomplete dentures Med Preg1Nov-Dec 1999; 52(11-12);464-68

[13] Piancino MG, Farina D, Talpone F, Castroflorio T, Gassino G, Margarino V, Bracoo P. surface EMG of jaw-elevator muscles and chewing pattern in complete denture wearers. Oral rehabil Dec 2005;32 (12);863-70

[14] Pancherz H. Temporal and masseter muscle activity in children 47. and adults with normal occlusion. An electromyographic investigation. Acta Odontol Scand; 1980, 38:343.

[15] Liu ZJ, Yamagata K, Kasahara Y, Ito G. Electromyographic examination of jaw muscles in relation to symptoms and occlusion of patients with tempromandibular joint disorders.jornal of Oral Rehabilitation 1999; 26; 33-47.

[16] Henriksson KL. Distribution, number and size of different types of fibers in whole cross sections of 


\section{International Journal of Science and Research (IJSR) \\ ISSN (Online): 2319-7064 \\ Index Copernicus Value (2013): 6.14 | Impact Factor (2015): 6.391}

female anterior tibias. An enzyme histochemical study. Acta Physil Scand; 1985, 123:229.

[17] Bingefors K, Isaccon D. Epidemiology, com-morbidity 49. and impact on health-related quality of life of selfreported headache and musculoskeletal pain- a gender perspective. Eur J Pain; 2004, 8:435-50.

[18] Kuba T, Quirones-Jenab V. The role of female gonadal 50. hormones in behavioral sex difference in persistent and chronic pain: clinical versus preclinical studies. Brain Res Bulletin; 2005, 66:179-88.

[19] Fillingim RB, Maixner W. The influence of resting blood 51. pressure and gender on pain responses. Psychosomatic Medicine; 1996, 58:326-32.

[20] Logan HL, Gedney JJ. Sex differences in the long-term stability 52. of fore head cold pressor pain. J Pain; 2004, 5:406-12.

[21] Pan S, Awad M, Thomson JM, Dufresne E, Kabayashi T, 53. Kimoto S, Wallin SD, Feine JS. Sex differences in denture satisfaction. J Dent; 2008, 36:301-308.

[22] Wyngoarden JB, Smith LH and Bennett JC. Cxecil's test book 54. of medicine. 19th ed., Philadelphia, WB, Sanders Co; 1992, 1401.

[23] VonGonten AS, Palik JE, Oberlader BA and Rugh JD. 55. Nocturnal electromyographic evaluation of the master activity in complete denture patient. J Prosthet Dent; 1986, 56:624.

[24]Henrikson T Ekberg EC and Nilner M. Masticatory efficiency 56. and ability in relation to occlusion and mandibular dysfunction in girls. Int $\mathrm{J}$ Prosthodont; 1988, 11:125.

[25] Basker RM and Watson CJ. Tongue control of upper complete 57. dentures: a clinical hint. Br Dent J; 1991, 170:449.

[26]Fenlon MR, Sherriff $M$ and Jhon Walter JD. Association 31. between the accuracy of intermaxillary relations and complete denture usage. J Prosthet Dent; 1999, 51:520.

[27] Dawson PE. A classification system for occlusions that relate maximal intercuspation to the position and condition of the temporo-mandibular joint. J Prosthet Dent; 1996, 75:60

[28] Khanna G, Aparna IN. Comparison of microhardness of three different types of artificial denture teeth; An in vitro study. J Orofac Res 2013;3;181-5.

[29] Col RK Dhiman , Lt Col SK Roy Chowdhury. Midline Fractures in Single Maxillary Complete Acrylic vs Flexible Dentures. MJAFI, Vol. 65, No. 2, 2009.

[30] Sutton AF, Glenny AM, McCord JF. Interventions for 60. replacing missing teeth denture chewing surface designs in edentulous people. Cochrane "Database Syst Rev; 2005: CD 004941.

[31] Castroflorio T, Bracco P, Farina D. Surface electromyography in the assessment of jaw elevator muscles, J Oral Rehabil 2008;35;638-45.

[32] Kapur KK, Soman SD. Masticatory performance and 63. efficiency in denture wearers. J Prosth Dent; 2004, 92(2): 107-111.

[33] Karakazis HC and Kossion AE. Surface EMG activity of the 64. masseter muscle in denture wearers during chewing of hard and soft food. J Oral Rehabil; 1998, $25: 8$.
[34] Slagter AP, Olttof LW, Steen WHA and Bosman F. 65. Communication of food by complete denture wearers. J Dent Res; 1992, 71:380.

[35] Olivo SA, Gadotti I, Kornerup M, Lagravere MO,Mir CF.quality of reporting masticatory muscle electromyography. A systemic review. J Oral Rehabil 2007; 34;397-405.

[36] Castroflrio T, Icardi K, Becchino B, Merlo E, Debernardi C, Bracco P, et al. reproducility of surface EMG variables in isometric submaximal contractions of jaw elevator muscles. J Electromyogr Kinesiiol 2006;16;498-505.

[37] Boerrigter EM, Stegenga B, Raghoebar GM, Boering G. 95. Patient satisfaction and chewing ability with implant-retained mandibular overdentures: a comparison with new complete dentures with or without preprosthetic surgery. J Oral Maxillofac Surg; 1995, 53:1167-1773.

[38] Wostmann, B.; Budtz-Jorgensen, E.; Jepson, N.; Mushimoto, E.; Palmqvist, S.; Sofou, A. \& Owall, B. (2005). Indications for removable dentures: a literature review.International Journal of Prosthodontics, Vol. 18, No. 2, pp. 139-145, (June 2005), ISSN0893-2174

[39] Van der Bilt A, van Kampen FMC, Cune MS. Masticatory function with mandibular-implantsupported overdenture fitted with different attachment types. Eur J Oral Sci 2006;114;191-6.

\section{Author Profile}

Souad A. Mussa Mesallati, received the B.D.S. in Dental and Oral Surgery from Benghazi University, Faculty of Dentistry 2008. During 2008-2009, she practiced in Ministry of Health. Since 2009-2012, she worked as a demonstrator in Benghazi University. During 2012 till now, she educated for M.S degree in prosthodontics in prosthetic department, Faculty of dentistry. Alexandria University. 